\title{
Effectiveness of Psychosocial-Based Resilience Intervention on Reducing Negative Emotional States Among Schizophrenia Caregivers
}

\author{
Valentino Marcel Tahamata \\ Faculty of Psychology, Universitas Diponegoro \\ vmtahamata@gmail.com \\ Dian Veronika Sakti Kaloeti \\ Center for Family Empowerment \\ Faculty of Psychology, \\ Universitas Diponegoro \\ dvs.kaloeti@live.undip.ac.id
}

\begin{abstract}
Schizophrenia caregivers are chronically exposed to a high level of negative emotional states such as depression, anxiety, and stress. Many studies have explored the problem among caregivers, but there remains to be limited evidence in the use of psychotherapeutic intervention to reduce schizophrenia caregivers' psychological adversities. This study aims to evaluate the effectiveness of psychosocialbased resilience intervention in reducing the negative emotional states of schizophrenia caregivers. The one group pre-post quasi-experimental design was conducted to five participants. Following the six sessions of training and two-weeks of follow-up, participants showed a significant reduction of negative emotional states $(p=.007)$, measured using the Depression, Anxiety, and Stress Scale (DASS$21)$. Furthermore, dimensions of negative emotional states were also significantly reduced i.e., depression $(p=.008)$, anxiety $(p=.015)$, and stress $(p=.016)$. These results provide evidence that psychosocial-based resilience program can effectively reduce the negative emotional states of schizophrenia caregivers.
\end{abstract}

Keywords: Resilience, Depression, Anxiety, Stress, Family Caregiver, Psychosis

Received I April 2019/Accepted 25 February 2020 @JEHCP All rights reserved

\section{Introduction}

Schizophrenia, characterized by delusion and hallucination (American Psychiatric Association, 20I3), is a severe, multi-factorial, and chronic mental illness that has continued to increase each year (WHO, 2018). Due to the chronic abnormal social behavior and failure in understanding reality, patients with schizophrenia require long-term caregiving. In a collectivist context, family plays a crucial role in fulfilling the needs of schizophrenia patients (Awad \& Voruganti, 2008; Ruiz- 
Robledillo \& Moya-Albiol, 2015). Recent studies revealed that understanding the caregiving process of people with schizophrenia and other chronic mental illness is essential. Family caregivers often face various problems in health insurance, finances, work, social stigma, as well as complications associated with the caregiving process itself (Chen et al., 2016; Ruiz-Robledillo \& Moya-Albiol, 20I5). Those challenges could generate negative psychological implications. Schizophrenia caregivers are exposed by a high level of psychological distress, anxiety, and depression through the caregiving process (Jain \& Singh, 2014; Ong, Ibrahim \& Wahab, 2016; Rodrigo, Fernando, Rajapakse, De Silva, \& Hanwella, 2013; Yusuf \& Nuhu, 20II). These circumstances relate to decreased quality of life, physiological impairments, and inappropriate caregiving to the patient (Kaushik \& Bhatia, 2013; Saarni, 2010; Sinha, Desai, Prakash, Kushwaha, \& Tripathi, 2017). Thus, highlighting the idea that psychological intervention needs to be formulated to promote mental health among schizophrenia caregivers (Chen et al., 2016).

Despite numerous previous studies on the negative implication of caregiving for schizophrenia patient, few studies have evaluated the effects of psychotherapies in reducing these negative states among family caregivers of severe and chronic mentally ill patients (López \& Crespo, 2007; Sorrel, 20I4; van Mierlo, Meiland, van der Roest, Dröes, 20I2). Several interventions has been tested to reduce the psychological burden of schizophrenia and other chronic mentally ill patients, such as the psycho-educational intervention, cognitive behavioral therapy, integrated psychosocial intervention, and family therapy (Caqueo-Urizar, Rus-Calafell, Urzua, Escudero \& GutiérrezMaldonado, 2015; Stanley \& Shwetha, 2006; Sharif, Shaygan, \& Mani, 2012). However, most studies analyzed caregivers of patients who suffer from stroke, cancer, dementia, and autism spectrum disorders. There is limited evidence on the effectiveness of these interventions in reducing the negative emotional state of schizophrenia caregivers (Ruiz-Robledillo \& Moya-Albiol, 20I5;Tonge, Brereton, Kiomall, Mackinnon, King, Rinehart, 2006).

Recent studies have shown contradicting findings, with family caregivers showing positive emotion and states as opposed to negative states. This finding seems to suggest that resilience plays a critical role in changing the negative state of being into positive outcomes (Chen et al., 20 I6; Fan, Chen, Lin, Bai, \& Wei, 20I4); Reivich \& Shatte, 2002; Seligman, 20II). Schizophrenia caregivers are supposed to be resilient. However, the high level of negative emotions and consequences implies that many caregivers are not resilient enough. Resilience emerged by one's self-efficacy to be adaptive in facing 
psychological adversity. In the context of schizophrenia caregiving, caregivers should be resilient for the sake of the patient as well as themselves (Reivich, Seligman, \& McBride, 20I I; Reivich \& Shatte, 2002; Cornum, Matthews \& Seligman, 20I I).

Fostering resilience has been proven to reduce one's negative emotional states in various contexts (e.g. preparing US sergeants in facing war, reduce work-related stress and burn-out in industrial and organizational settings, help emergency services personnel to cope with trauma and anxiety symptoms, reduce psychological distress and elevate the positive emotions of Chinese medical students (Cornum, Matthews, \& Seligman, 20II, Peng et al., 20I4; Vanhove, Herian, Perez, Harms, \& Lester, 20I5; Varker \& Devilly, 20I2). In this study, negative emotional states are defined as the presence of depression, anxiety, and stress, classified as the primary negative emotions (Lovibond \& Lovibond, 1995) and undergone by the schizophrenia caregivers as aforementioned. Resilience aids schizophrenia caregiver to adjust with this adverse condition, and train them to be resilient. Caregivers are trained to stay composed in all situations and deal with the negative emotions that might arise. Thus, we hypothesized that caregivers would get a significantly lower negative emotional state after receiving the psychosocial-based resilience training program, as previously described.

\section{Method}

\section{Participants and Procedure}

The sample consisted of five caregivers (four women and one man) who had cared for their nuclear family diagnosed with schizophrenia. Most participants came from a low educational and socioeconomic background and were aged 50 on average. Participants were married and lived in rural areas in Central Java, Indonesia. Caregivers were recruited from villagers in the working area of Pusat Kesehatan Masyarakat Rejosari [Rejosari Health Center]. Screening was conducted to select eligible caregivers based on the inclusion criteria: (I) nuclear family of patient, (2) reside with the patient, (3) full-time caregiver of the patient, (4) classified as having a 'severe' or 'extremely severe' level of depression, anxiety, and stress based on DASS-2I, and (5) willing to participate in the research. There were 52 screened caregivers from 70 family caregivers in the working area of Rejosari Health Center. The screening process found that ten caregivers meet the inclusion criteria. 
Next, all ten eligible caregivers were invited to the training - six of them attended the first session of training before $\mathrm{a}-$

Table I

The psychosocial-based resilience training manual

\begin{tabular}{|c|c|c|}
\hline & Session & Content \\
\hline Initial Session & 'Let's Break The Ice' & $\begin{array}{l}\text { - Introducing self (both participants and } \\
\text { researchers) } \\
\text { - Conveying the research aim and terms }\end{array}$ \\
\hline Session I & 'Caregiver's Self-Concept' & $\begin{array}{l}\text { - Reflection: Human's potential as a special } \\
\text { creature on this earth } \\
\text { - Basic orientation of Resilience in Caregiving } \\
\text { Schizophrenia Patient }\end{array}$ \\
\hline Session 2 & 'Emotional Literacy' & $\begin{array}{l}\text { - Understanding emotion } \\
\text { - Introducing 'breathe control' / relaxation and } \\
\text { practice } \\
\text { - Introducing 'Self-Talk' and practice }\end{array}$ \\
\hline Session 3 & $\begin{array}{l}\text { 'Reflective Thinking and } \\
\text { Impulse Control' }\end{array}$ & $\begin{array}{l}\text { - Introducing thought record (ABC model) and } \\
\text { practice for own self and others } \\
\text { - Sharing personal experiences in caregiving to } \\
\text { other participants in the } A B C \text { model }\end{array}$ \\
\hline Session 4 & 'Empathy' & $\begin{array}{l}\text { - Understanding patients' psychological state of } \\
\text { being } \\
\text { - Identifying and reflecting patients' feeling }\end{array}$ \\
\hline Session 5 & $\begin{array}{l}\text { 'Self-Efficacy and } \\
\text { Optimism' }\end{array}$ & $\begin{array}{l}\text { - Discovering the efficacy and optimism in } \\
\text { caregiving } \\
\text { - Playing a relevant game and watching the video to } \\
\text { stimulate the vicarious experience }\end{array}$ \\
\hline Session 6 & 'Reaching Out' & $\begin{array}{l}\text { - Identifying appropriate and inappropriate behavior } \\
\text { in caregiving } \\
\text { - Making a patient empowerment program. } \\
\text { - Making joint commitment to care for the patient } \\
\text { appropriately and realize the empowering } \\
\text { program }\end{array}$ \\
\hline
\end{tabular}

Tahamata \& Kaloeti (20I8). Adapted from Reivich \& Shatte (2002). 
caregiver dropped-out. Thus, only five participants were involved in this psychosocial-based resilience training. This study was conducted using the quasi-experimental with one group pre-post design. The initial session was made to introduce participants to the training and explain the aim and terms of research that should be conveniently followed by participants and researchers. The training was integrated by the concept of resilience proposed by Reivich and Shatte (2002). The intervention program contained six 2-hours sessions successively for six days.After the $6^{\text {th }}$ day of training, 2-weeks follow-up sessions were conducted independently using a checklist. The checklist activities were represented the 6-days of training sessions. The content of the intervention is summarized in Table I. Furthermore, the negative emotional states of schizophrenia caregivers were evaluated before and after the intervention. The procedure of evaluation was conducted by repeated measurements i.e., pre-test (first day of training), post-test (last day of training), follow-up (2-weeks follow-up session).

Instrument

The Depression, Anxiety, and Stress Scale (DASS-2I items) were employed to assess the level of negative emotional states among caregivers in the pre-test, post-test, and follow-up session. DASS21 consists of three subscales, assessing the dimensions of negative emotional states (i.e., depression, anxiety, and stress). Each dimension is made up of seven items. DASS-2I is a 4-point Likert scale from 0 (never) to 3 (frequently occur in the last two weeks) with a .94 Chronbach's Alpha reliability coefficient. Furthermore, the total number of the scale was also calculated (score of negative emotional states).

\section{Statistical Analysis}

Friedman test was employed to explore changes in participants' negative emotional states over time (comparing the score of pre-test, post-test, and follow-up). Next, Wilcoxon Signed Range Test was performed to compare the pre-test to post-test and post-test to follow-up scores. All the statistical analyses were done using the IBM SPSS Statistics (version 23.0). 


\section{Results}

There were significant changes over time in depression $(p=.008)$, anxiety $(p=.015)$, and stress $(p$ $=.016)$ as well as overall score of negative emotional states $(p=.007)$ based on Friedman Test. Additionally, we found a moderate effect size on pre-test to post-test measurement $(d=.678)$ and small effect size on the post-test to follow-up measurement $(d=.243)$.

The significant reductions were also found in pre-test to post-test score of negative emotional states $(p=.043 ; Z=-2.023)$, depression $\left(p=.042 ; Z=-2.023 ; \eta_{\text {partial }}^{2}=.320\right)$, anxiety $(p=.039 ; Z=-$ 2.06; $\left.\eta_{\text {partial }}^{2}=.642\right)$, and stress $\left(p=.042 ; Z=-2.023 ; \eta_{\text {partial }}^{2}=.352\right)$. In contrary, scores of depression $\left(p=.066 ; Z=-1.84 I ; \eta_{\text {partial }}^{2}=.567\right)$, anxiety $\left(p=.074 ; Z=-1.786 ; \eta_{\text {partial }}^{2}=.518\right)$ and stress $(p$ $\left.=.131 ; Z=-1.512 ; \eta_{\text {partial }}^{2}=.489\right)$ were not significant in the post-test to follow-up measurement, while the score of negative emotional state $(p=.043 ; Z=-2.023)$ was significant. The greatest discrepancy occurred in the score of depression $\left(M_{\text {pretest }}=27.6 \pm 5.899 ; M_{\text {posttest }}=17.2 \pm 6.261\right.$; $M_{\text {followup }}=(2.8 \pm 4.56 \mathrm{I})$, followed by

Table 2

Pre-test, post-test, and follow-up test score of each participant

\begin{tabular}{|c|c|c|c|c|c|c|}
\hline \multicolumn{2}{|c|}{ Measurements } & \multicolumn{5}{|c|}{ Participants } \\
\hline & & I & 2 & 3 & 4 & 5 \\
\hline & Pre-test & $24^{d)}$ & $24^{d)}$ & $34^{\mathrm{e})}$ & $34^{\text {e) }}$ & $22^{d)}$ \\
\hline \multirow[t]{3}{*}{ Depression } & Post-test & $14^{c)}$ & $16^{c)}$ & $28^{\mathrm{e})}$ & $12^{b)}$ & $16^{c)}$ \\
\hline & Follow-up & $14^{c)}$ & $14^{c)}$ & $22^{d)}$ & $10^{b)}$ & $12^{b)}$ \\
\hline & Pre-test & $20^{\text {e) }}$ & $24^{\text {e) }}$ & $32^{\text {e) }}$ & $28^{\mathrm{e})}$ & $28^{\mathrm{e})}$ \\
\hline \multirow[t]{3}{*}{ Anxiety } & Post-test & $16^{d)}$ & $20^{\text {e) }}$ & $26^{\mathrm{e})}$ & 20 e) & $24^{\mathrm{e})}$ \\
\hline & Follow-up & $12^{c)}$ & $16^{d)}$ & $28^{\mathrm{e})}$ & $16^{d)}$ & $18^{d)}$ \\
\hline & Pre-test & $30^{d)}$ & $26^{d)}$ & $36^{e)}$ & $24^{c)}$ & $26^{d)}$ \\
\hline \multirow[t]{2}{*}{ Stress } & Post-test & $18^{b)}$ & $24^{c)}$ & $30^{d)}$ & $18^{b)}$ & $16^{b)}$ \\
\hline & Follow-up & $14^{\text {a) }}$ & $20^{c)}$ & $32^{d)}$ & $18^{b)}$ & $12^{\text {a) }}$ \\
\hline \multirow{3}{*}{$\begin{array}{l}\text { Negative } \\
\text { Emotional } \\
\text { States } \\
\text { (Overall Score) }\end{array}$} & Pre-test & 37 & 37 & 51 & 43 & 38 \\
\hline & Post-test & 24 & 30 & 42 & 25 & 28 \\
\hline & Follow-up & 20 & 25 & 41 & 22 & 21 \\
\hline
\end{tabular}

${ }^{\text {a) }}=$ Normal; ${ }^{\text {b) }}=$ Mild; ${ }^{\text {c) }}=$ Moderate; ${ }^{\text {d) }}=$ Severe; ${ }^{\text {e) }}=$ Extreme Severe 
anxiety $\left(M_{\text {pretest }}=26.4 \pm 4.561 ; M_{\text {posttest }}=2.12 \pm 3.889 ; M_{\text {followup }}=18.0 \pm 6.000\right)$ and stress $\left(M_{\text {pretest }}=\right.$ $\left.28.4 \pm 4.755 ; M_{\text {posttest }}=21.2 \pm 5.762 ; M_{\text {followup }}=19.2 \pm 7.823\right)$. The statistical reduction of negative emotional states is shown in Figure I. Table 2 depicts the various dynamics of negative emotional state reduction of each participant.

Table 2 shows that participant 3 experienced an increased level of anxiety and stress as well as a stagnant score in depression during the post-test to follow-up measurement. On the other hand, participant 2, 4, and 5 showed a stable score reduction in all negative emotional state dimensions at both the pre-test to post-test and post-test to follow-up measurements.

\section{Table 3}

Percentage of Participants Compliance to fulfill 2-weeks Follow-up Sessions

\begin{tabular}{ccccc}
\hline Participant I & Participant 2 & Participant 3 & Participant 4 & Participant 5 \\
\hline $66.65 \%$ & $90 \%$ & $63.08 \%$ & $100 \%$ & $100 \%$ \\
\hline
\end{tabular}

Researchers investigated the compliance level of each participant in fulfilling the 2-weeks follow-up checklist to find an explanation for the elevation and stagnation score in Participant I and 3. Table 3 illustrates the participant's compliance. Participant I and 3 have fulfilled approximately $60 \%$ of the total activity by the follow-up sessions. This circumstance correlates with the ascending point and stagnation of anxiety and stress score during the post-test to follow-up measurement of participant $\mathrm{I}$ and 3 , as well as the steady decrease in all measurements for participant 2, 4, and 5.

\section{Discussion}

The present study examined the efficacy of psychosocial-based resilience training to decrease the negative emotional state of schizophrenia caregivers. The psychotherapeutic strategies employed in this study have previously been found to be effective in several studies (Cornum, Matthews, \& Seligman, 20II; Penget al., 20I4; Varker \& Devilly, 20I2; Vanhoveet al., 20I5). However, this recent study implemented the intervention in another context. Resilience training is effective in reducing health risk, stress reactivity, and aggression among law enforcement officers who are highly exposed by a great level of psychological distress and work-related risk in health (Christopher et al., 2018). 


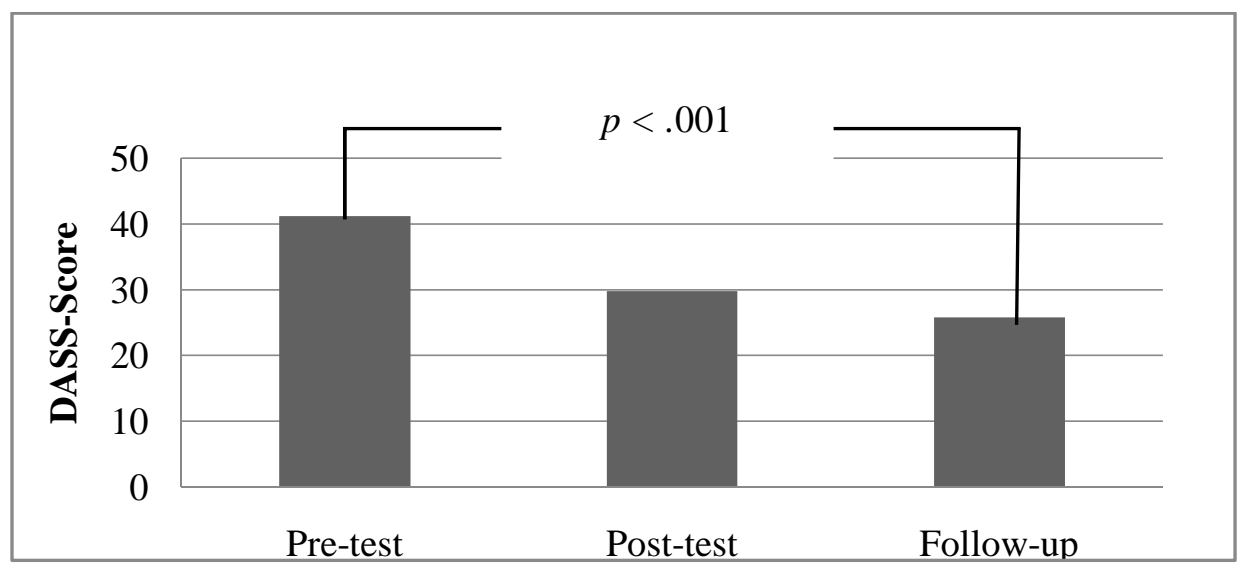

Figure I. Overall negative emotional state scores in pretest, post-test, and 2-weeks follow-up

Resilience also contributes to the reduction of psychological symptoms in as many as 170 family members with a critical illness (i.e., depression, anxiety, acute stress) (Sottile, Lynch, Mealer, \& Moss, 2017).To our knowledge, this is the first study to evaluate the application of psychosocialbased resilience training for schizophrenia caregivers in a rural community.

The intervention aims to strengthen caregivers' skills in reducing their negative emotional state and create positive emotions (Burton, Pakenham, Brown, 2010; Grant \& Kinman, 2015). The applied intervention also addressed common inappropriate behaviors often found in caregiving (e.g., hitting the patient, being unfriendly, giving improper medical and psychological treatments shown through the presence of negative emotional states). Several programs, both in concept and practice, as well as follow-up checklist homework, were incorporated into this intervention to aid caregivers. The following programs were designed to increase caregivers' comprehension in becoming a proper caregiver: Human's potential as a special creature, understanding emotions, and discovering schizophrenia. On the other hand, the following sessions aim to increase caregivers' resilience: breathe control, self-talk, $A B C$ thought model, making an empowering program, and joint commitment to care for the patient (Reivich \& Shatte, 2002). Participants were eager to create a proper caregiving formula in their context. They identified the inappropriate behavior they made and formulated the appropriate caregiving. Participants also committed to involve the patient in their daily activity and allocate specific chores that patients could do (e.g., cooking, farming). 
The present findings support previous studies in that resilience plays a critical role in changing adversity into strength (Chen et al., 2016; Fan et al., 20I4). There was a significant decrease in the negative emotional state scores and its' dimensions (i.e., depression, anxiety, stress). On the other hand, those dimensions have not significantly decreased during the 2-weeks follow-up measurement. During the follow-up session, researchers found various levels of participants' compliance in practicing the checklist, which might explain this lack of significant decrease. Participant I and 3 , practiced approximately $60 \%$ of the total activity by the follow-up session. Participant 2 conducted $90 \%$ of the sessions, while participants 4 and 5 performed the given task in all sessions. The individual analysis confirmed these circumstances by the most significant reduction score in negative emotional states occurred on Participant 4 and 5. On the other hand, participant I and, particularly participant 3, showed a non-significant, stagnant, and increase in anxiety and stress. These findings also confirmed that resilience training should be practiced in everyday life (Reivich \& Shatte, 2002).

The statistical analysis shows the different significance of the negative emotional state reduction. The overall score of negative emotional states and depression significance $(p)$ were $<.00$ I, while the significance $(p)$ in anxiety and stress were $<.005$. Previous studies showed that the emotion that fluctuates the most is depression (Edimansyah, Rusli, \& Naing, 2008; King, 2010). Moreover, it is difficult for psychological interventions to reduce stress and anxiety that are caused by multiple factors (e.g., socioeconomic status, social stigma, symptoms of schizophrenia) (King, 20l0). Additionally, culture plays a critical role in promoting mental health among people. Collectivist people develop a collective resilience in which the community helps someone to adapt to their adverse life event (Beelet al., 20I5). Moreover, Lim (2016) stated that culture influences the differences in level of emotional arousal, whereby collectivist people experience lower arousal than western people. This state of emotional arousal aids people in regulating their inflicted emotions.

\section{Limitation}

This study remains limited by several conditions (i.e., researchers only screened 52 out of the 80 family caregivers in the working area of Rejosari Health Center). Furthermore, participants were not at the same level of severity, and a few numbers of participants may bring a bias in statistical regression. Additionally, from 52 screened caregivers, only ten caregivers possessed 'severe' and 'extremely severe' levels of depression, anxiety, and stress. This fact implies that most caregivers 
have successfully managed their negative emotions. We also found that the effect size of this study was moderate in the pre-test to post-test and small in the post-test to follow-up-test. Overall, the study revealed the efficacy of psychosocial-based resilience training in reducing the negative emotional states of schizophrenia caregivers in the rural collectivist community context.

\section{Recommendation}

Further study should attempt to qualitatively explore the dynamics of emotional responses of schizophrenia caregivers in the Javanese rural context. This is mainly because most of them show very low negative emotional states. We also encourage future researchers to increase the size of the participants involved in this intervention and specifically recruit participants who were classified as having "extremely severe" in DASS-21. We believe this could generate a greater contrast for the statistical results. Moreover, comparing the effectiveness of this intervention in other populations (e.g., different tribes or socioeconomic background) would provide a more comprehensive view about resilience training.

\section{References}

American Psychiatric Association. (2013). Diagnostic and statistical manual of mental disorders (5th ed.). Arlington, $V A$

Awad, A. G., \& Voruganti, L. N. (2008). The burden of schizophrenia on caregivers. Pharmacoeconomics, 26(2), 149-162.

Beel, D. E., Wallace, C. D., Webster, G., Nguyen, H., Tait, E., Macleod, M., \&Mellish, C. Cultural resilience: The production of rural community heritage, digital archives and the role of volunteers. Journal of Rural Studies, 5, I-I0.

Burton, N.W., Pakenham, K. I., \& Brown, W. J. (2010). Feasibility and effectiveness of psychosocial resilience training: a pilot study of the READY program. Psychology, Health \& Medicine, 15(3), 266-277.

Caqueo-Urizar, A., Rus-Calafell., Urzua, A., Escudero, J., \& Gutiérrez-Maldonado, J . (2015). The role of family therapy in the management of schizophrenia: challenges and solutions. Neuropsychiatric Disease Treatment, I4(II), 145-15I.

Chan, S. W. (201I). A global perspective of the burden of family caregivers for persons with schizophrenia. Archives of Psychiatric Nursing, 25(I), 339-349.

Chen, X., Mao, Y., Kong, L., Li, G., Xin, M., Lou, F., \& Li, P. (2016). Resilience moderates the association between stigma and psychological distress among caregivers of patients with schizophrenia.Personality and Individual Differences, 96(I) 78-82. 
Christopher, M. S., Hunsinger, M., Goerling, L. R. J., Bowen, S., Gross, C.R., Dapolonia, E., \& Pruessner, J.C. (20/8). Mindfulness-based resilience training to reduce health risk, stress reactivity, and aggression among law enforcement officers: A feasibility and preliminary efficacy trial. Psychiatric Research. 264, 104-I I 5.

Cornum, R., Matthews, M. D., \& Sligman, M. E. (201 I). Comprehensive Soldier Fitness Building Resilience in a Challenging Institutional Context. American Psychologist, 66(I), 4-9.

Edimansyah, B.N., Rusli, B. A., \& Naing, L. (2008). Working conditions, self-perceived stress, anxiety, depression, and quality of life: A structural equation modeling approach. BMC Public Health, 8(48), 78-89.

Fan, Y. C., Chen, M. B., Lin, K. C., Bai, Y. M. \& Wei, S. J. (20I4). The resilience and health status of primary caregivers of schizophrenia patients. Hu Li ZaZhi [The Journal of Nursing], 6I: 29-38.

Grant, L., \& Kinman, G. (20I5). Guide to developing emotional resilience. London: Palgrave.

Jain, A., \& Singh, D. C. (20I4). Resilience and quality of life in caregivers of schizophrenia and bipolar disorder patients. Global Journal of Human Social Science, I4(5): 25-28.

Kaushik, P., \& Bhatia, M. S. (2013). Burden and quality of life in spouses of patients with schizophrenia and bipolar disorder. Delhi Psychiatry Journal, I6(I): 83-89.

King, L. (2010). The science of psychology. USA: McGraw Hill.

Lim, N. (20I6). Cultural differences in emotion: differences in emotional arousal level between the East and the West. Integrative medicine research, 5(2), 105-109.

López, J. \& Crespo, M. (2007). Interventions for caregivers of older and dependent adults: a review. Psicothema, 19, 72-80.

Lovibond, P. F., \& Lovibond, S. H. (1995). The structure of negative emotional state: comparison of The Depression Anxiety Stress Scale (DASS) with The Beck Depression and Anxiety Inventories. Behaviour Research and Therapy, 33(3), 335-343.

Ong, H. C., Ibrahim, N., \& Wahab, S. (2016). Psychological distress, perceived stigma, and coping among caregivers of patients with schizophrenia. Psychology Research and Behavior Management, 9, 211-218.

Peng, L., Min, L., Zuo, X., Miao, Y., Chen, L., Yu, Y., Liu, B., \& Wang, T. (20I4). Application of the Pennsylvania resilience training program on medical students. Personality and Individual Differences, 6I, 47-5I.

Reivich, K. J., \& Shatte, A. (2002). The resilience factor: 7 essential skills for overcoming life's inevitable obstacle. New York: Broadway Books.

Reivich, K. J., Seligman, M. E., \& McBride, S. (20II). Master resilience training in the U.S. Army. American Psychologist, 66(I), 25-34.

Rodrigo, C., Fernando, T., Rajapakse, S., De Silva, V., \& Hanwella, R. (20I3). Caregiver strain and symptoms of depression among principal caregivers of patients with schizophrenia and bipolar affective disorder in Sri Lanka. International Journal of Mental Health System, 7(2), I-5.

Ruiz-Robledillo, N. \& Moya-Albiol, L. (2015). Effects of a cognitive-behavioral intervention program on the health of caregivers of people with an autism spectrum disorder. Psychosocial Intervention. 24, 33-39.

Saarni, S. I. (2010). Quality of life of people with schizophrenia, bipolar disorder, and other psychotic disorders. British Journal of Psychiatry, 32(4), 84-91. 
Seligman, M. (20I I). Flourish: A new theory of positive psychology. Boston: Nicholas Brealey Publishing. Sharif, F., Shaygan, M., \& Mani, A. (20I2). Effect of a psycho-educational intervention for family members on caregiver burdens and psychiatric symptoms in patients with schizophrenia in Shiraz, Iran.BMC Psychiatry, I2(48), I-9.

Sinha, P., Desai, N. G., Prakash, O., Kushwaha, S., \& Tripathi, C. B. (2017). Caregiver burden in Alzheimer-type dementia and psychosis: A comparative study from India. Asian Journal of Psychiatry, 26(I), 86-9I.

Sorrel, J. M. (2014). Moving beyond caregiver burden: Identifying helpful interventions for family caregivers. Journal of Psychosocial Nursing and Mental Health Services. 52, 15 - 18.

Sotille, P. D., Lynch, Y., Mealer, M., \& Moss, M. (2016). Association between resilience and family member psychologic symptoms in critical illness. Critical Care Medicine, 44(8), I34-I 48.

Stanley, S., \&Shweta, S. (2006) Integrated psychosocial intervention in schizophrenia: Implications for patients and caregivers. International Journal of Psychosocial Rehabilitation, 10 (2), II3-I 28.

Tonge, A., Brereton, M., Kiomall, A., Mackinnon, N., King, N., \& Rinehart, N. (2006). Effects on the parental mental health of an education and skills training program for parents of young children with autism: A randomized controlled trial. Journal of the American Academy of Child and Adolescent Psychiatry, 45, 56I-569.

Van Mierlo, L.D., Meiland F.J., Van der Roest, H.G., \& Dröes, R.M. (20I2). Personalized caregiver support: effectiveness of psychosocial interventions in subgroups of caregivers of people with dementia. International Journal of Geriatric Psychiatry, 27, I-I4.

Vanhove, A. J., Herian, M. N., Perez, A. L. U., Harms, P. D., \& Lester, P. B. (20I5). Can resilience be developed at work? A meta-analytic review of resilience-building programme effectiveness. Journal of Occupational and Organizational Psychology, 89(2), 278-307.

Varker, T., \& Devilly, G. J. (20I2). An analog trial of inoculation resilience training for emergency services personnel: proof of concept. Journal of Anxiety Disorder. 26(6), 696-70I.

World Health Organization. (2018). Schizophrenia. Retrieved from http://www.who.int/newsroom/fact-sheets/detail/schizophrenia.

Yusuf, A.J., \& Nuhu, F.T. (20II). Factors associated with emotional distress among caregivers of patients with schizophrenia in Katsina, Nigeria. Social Psychiatry and Psychiatric Epidemiology, $46(1), 11-16$. 